\title{
Parental Satisfaction on Multiple Daily Injections, Insulin Pump and Flexible Multiple Daily Injections Used for Children with Type 1 Diabetes Mellitus
}

\author{
Anutosh Shee ${ }^{1}$, Sarah Prior $^{2}$, Nicole Reeves ${ }^{2}$, Maria Smith $^{3}$, Sharon Luccisano ${ }^{3}$ \\ ${ }^{1}$ Department of Paediatrics, University of Tasmania, Tasmania, Australia \\ ${ }^{2}$ Clinical School, University of Tasmania, Tasmania, Australia \\ ${ }^{3}$ Tasmanian Health Service, Tasmania, Australia
}

\section{Email address:}

anutosh.shee@ths.tas.gov.au(A. Shee), sarah.prior@utas.edu.au(S. Prior), nicole.reeves@utas.edu.au(N. Reeves), maria.smith@ths.tas.gov.au (M. Smith),sharon.luccisano@ths.tas.gov.au(S.Luccisano)

\section{To cite this article:}

Anutosh Shee, Sarah Prior, Nicole Reeves, Maria Smith, Sharon Luccisano. Parental Satisfaction on Multiple Daily Injections, Insulin Pump and Flexible Multiple Daily Injections Used for Children with Type 1 Diabetes Mellitus. American Journal of Pediatrics.

Vol. 5, No. 2, 2019, pp. 43-50. doi: 10.11648/j.ajp.20190502.12

Received: December 16, 2018; Accepted: January28, 2019; Published: May 10, 2019

\begin{abstract}
Aims: This study aims to identify differences in parental satisfaction between three distinct types of intensive insulin therapies used for children with type 1 diabetes (T1D) namely multiple daily injection (MDI), continuous subcutaneous insulin infusion (CSII) and flexible multiple daily injection (fMDI). Materials and Methods: Data was collected over a 6-month period during the quarterly clinic visits. Two modified versions of validated tools- Insulin Treatment Satisfaction Questionnaire (ITSQ) and Diabetes Treatment Satisfaction Questionnaire (DTSQ), were electronically filled in by the parents of children with T1D. This provided information on parental satisfaction on the following areas: inconvenience of regimen, lifestyle flexibility, impression of glycaemic control, fear of hypoglycaemia, diabetic symptoms, treatment barriers, worry, treatment adherence and communication. Results: 34 parents completed the electronic data forms on iSurvey. Parents of the fMDI group were the most confident to avoid severe hypoglycaemia whereas MDI-parents being the least confident, $\mathrm{t}(21)=2.12, p=$ 0.046. There was no statistical difference noted on how confident parents felt to avoid asymptomatic hypoglycaemia, their worry about nocturnal hypoglycaemia, convenience and ease of using insulin in public places, nor was there statistically significant difference in the pain and discomfort felt by their children. Parents of children with fMDI felt the time their children spent with hyperglycemia was higher than the MDI, t $(21)=2.11, p=0.047$. Parents of the CSII group were most likely to continue their current treatment and were also, most likely to recommend the treatment regimen to others. Parents of MDI were least likely to do so, $\mathrm{t}(20)=2.12, p=.047$ and $\mathrm{t}(18)=2.35, p=0.031$. Conclusion: Although this study was conducted with a very small sample size, it has revealed no significant difference in parental satisfaction among MDI, CSII and fMDI groups including parental anxiety and stress, ease of use in public places, convenience, flexibility, parental perception of pain and discomfort experienced by their children and fear of nocturnal hypoglycaemia. However, parents indicated greater confidence in avoiding severe hypoglycaemia in fMDI albeit there was higher glycaemic variability. Parents with CSII were more satisfied with treatment and more likely to recommend their current treatment option to others, than fMDI and MDI, as the preferred mode of treatment.
\end{abstract}

Keywords: Type 1 Diabetes Mellitus, Continuous Subcutaneous Insulin Infusion, Flexible Multiple Daily Injection, Multiple Daily Injection, Insulin Treatment Satisfaction Questionnaire,

Diabetes Treatment Satisfaction Questionnaire

\section{Introduction}

These are exciting times in the realm of management of type 1 diabetes (T1D), one of the most common chronic medical conditions affecting children and young adults with a worldwide prevalence of nearly half a million children below 
14 years (International Diabetes Federation, 2013). [1] Poorly controlled T1D can be life- threatening and eventually lead to long term microvascular complications such as retinopathy and nephropathy. The availability of evolving technologies such as flash glucometer, continuous glucose monitoring systems, devices with reduced need for insulin injection prick (e.g. i-port advance), sensor augmented insulin pump, artificial pancreatic system and different types of insulin analogues, are continuously changing the way T1D is treated, impacting variable treatment satisfaction. Emerging insulin delivery and glucose monitoring systems aiming for a better glycemic control, can often be counterproductive due to the significant overload of digital information. Families with various affective, behavioral, and cognitive characteristics may derive different benefit from a specific type of insulin regimen.

Diagnosis of T1D in children is a life changing event for the entire family with profound impact on emotional wellbeing and quality of life (QoL) for both children and their parents. The mainstay of the treatment of T1D today is the intensive insulin therapy delivered either by continuous subcutaneous insulin infusion (CSII) or multiple daily injections- by fixed dose (MDI) or by flexible dose adjusted to carbohydrate intake (fMDI). Twice-daily insulin regimen (BD) has largely been made obsolete because of outcome data on microvascular complications from the landmark Diabetes Control and Complication Trial. [2] A flexible version of multiple daily injection, fMDI is currently gaining popularity with distinct advantage of better meal quality flexibility requiring to inject variable doses of insulin based on the carbohydrate intake. The overall decision while selecting the right insulin treatment strategy and glucose monitoring system should not only depend on glycemic control but also to the QoL and treatment satisfaction for both parents and children. In terms of controlling T1D, type of intensive insulin regimen is relevant. One meta-analysis of the seven RCTs involving 220 children with T1D demonstrated that CSII was associated with statistically significant, but, only with marginal decrease in $\mathrm{HbA1c}$ level ( $\mathrm{MD}=-0.24 \%, 95 \% \mathrm{CI}=-0.41$ to -0.07$)$ compared to MDI. This meta-analysis demonstrated no significant differences in episodes of severe hypoglycemia (SH) and diabetic ketoacidosis (DKA) compared to MDI [3]. The largest study in this regard was the SWEET (Better control in Pediatric and Adolescent diabeteS: Working to crEate CEnTers of Reference) registry which compared glycemic control between patients treated with CSII vs MDI. The SWEET study included 16,570 children with T1D and showed that both $\mathrm{HbA} 1 \mathrm{c}$ and daily insulin dose $(\mathrm{U} / \mathrm{kg} / \mathrm{d})$ remained decreased in children treated with CSII compared to MDI (P $<.0001)$. [4] Other studies demonstrated that CSII is associated with equivalent short term but significantly improved sustained glycemic control, especially in preschool children in motivated families, with higher treatment satisfaction and improved QoL for children. [5] [6] In a systematic review, parental QoL was reported in two out of seven studies, with one study reporting no significant improvement in CSII group compared to MDI but the other reported significant reduction in diabetes-related worry in CSII and increased frequency of stress in MDI. [3] Some of the factors that may potentially influence parental satisfaction and QoL include age of their children, duration of T1D, presence of comorbidities, type of insulin regime and delivery (pen vs syringe and needle), associated use of CGM, type of insulin (analogue vs human), presence of sensors augmentation in the pump, previous history of severe hypoglycemia, parental fear of hypoglycemia, additional requirement of carbohydrate counting and supportive school environment. In this study we focused on the impact of types of insulin regimen on the parental treatment satisfaction. Although comparison of MDI and CSII on parental satisfaction has been studies, data comparing fMDI with other two is lacking. The aim of this study was also to identify additional considerations when recommending the most appropriate regimen of treatment in T1D.

\section{Materials and Methods}

\subsection{Participants}

Parents of children with T1D who are using one of three types of insulin regimen; CSII, MDI and fMDI.

\subsection{Procedure}

This survey-based study was conducted in the north west region of Tasmania, with the approval of, and, in accordance with the policies and procedures of the University of Tasmania Health and Medical Human Research Ethics Committee. A self-report questionnaire along with modified version of Insulin Treatment Satisfaction Questionnaire and Diabetes Treatment Satisfaction Questionnaire were created on an electronic tablet using iSurvey application. The deidentified information was then collected electronically before downloading into an excel spreadsheet and SPSS V24.0 for further analysis.

\subsection{Materials}

The questionnaire was divided into four main sections:

\subsubsection{Demographics and General Questions}

This 20 -item questionnaire was completed by parents and included their demographic information and the medical history of the child.

\subsubsection{The Insulin Treatment Satisfaction Questionnaire (ITSQ; Anderson et al)}

This is a 22-item questionnaire designed to measure treatment satisfaction for individuals with diabetes treated with insulin. The questionnaire was amended to assess treatment satisfaction perceived by the parents. The ITSQ consists of five satisfaction domains: Inconvenience of regimen (5 items); Lifestyle flexibility (3 items); Glycemic control (3 items); Hypoglycemic control (5 items) and Insulin delivery device (6 items). Items are measured on a 
7-point Likert scale where lower scores indicate greater confidence $(1=$ extremely convenient to $7=$ not at all convenient). Questionnaire items are transformed to a scale of $0-100$ with higher scores indicating better treatment satisfaction. For each subscale, the sum score is divided by number of items.

\subsubsection{Diabetes Treatment Satisfaction Questionnaire (DTSQ)}

This 8 -item questionnaire was completed by parents to evaluate their satisfaction with the current diabetes treatment regimen for their child. The questions were adapted from a previously validated questionnaire (Bradley \& Bradley, 1994). The DTSQ measures overall satisfaction, convenience, flexibility, understanding of diabetes, willingness to recommend current treatment and to continue current treatment. Each item is rated on a 7point Likert scale where higher scores indicate greater levels of satisfaction $(0=$ 'very dissatisfied' to $6=$ 'very satisfied'). Items two and three assess glycemic control and are rated differently $(0=$ 'never' to $6=$ 'most of the time'). All items except items 2 and 3 are summed to produce a total score $(0-36)$. Higher scores indicate higher treatment satisfaction.

\section{Results}

\subsection{Demographics and General Questions}

A total of 35 parents of children with T1D were enrolled for the study during their quarterly clinic visit. One withdrew before administering the questionnaire due to time constraint. Twenty of them were between 30-49 years age. Only two parents were of aboriginal Australian descent. Most of the respondents were employed either, in fulltime or casual jobs. Nearly one third of all respondents were either, an advanced diploma holder or above. Fifty percent of the parents were married. Table 1, shows the demographic information for the parents. The study group, (see Table 2), indicated only $10 \%$ of all the children with T1D were below 8 years old. Overall, there were an equal number of boys and girls. Three in every four children had acceptable BMI and 5\% were obese. In this cohort, half of all children had poor glycemic control as defined by HbAlc being above $9 \%$, possibly due to a high proportion of adolescents. 14 children were using MDI (14/35) followed by 11children who were on CSII (11/35) and the least number of children, 10 were administering fMDI (10/35) in this cohort. (Figure 1) The treatment modality for each child had been selected by the treating pediatricians as per the child's clinical needs and in consultation with the family. Fourteen children $(40 \%)$ had previously switched from MDI to a different type of insulin regimen (fMDI or CSII). Insulin Glargine, as a long acting and Insulin aspart and lispro as short-acting insulin analogue delivered through the pen device for both fMDI and MDI regimen. Insulin aspart was used for all the children with CSII in our cohort.

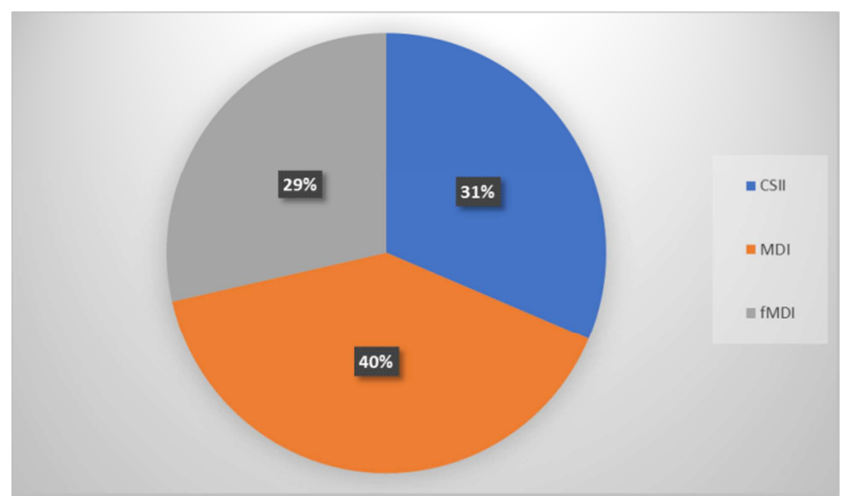

Figure 1. The pie chart showing the proportion of the children and adolescents being treated by CSII, MDI and fMDI.

Table 1. Demographic Information of Parents of Children with Type 1 Diabetes.

\begin{tabular}{|c|c|}
\hline Variables & $n=34$ \\
\hline \multicolumn{2}{|l|}{ Age } \\
\hline $18-29$ & 5 \\
\hline $30-49$ & 20 \\
\hline $50-64$ & 8 \\
\hline $65+$ & 1 \\
\hline \multicolumn{2}{|l|}{ Education } \\
\hline Less than year 12 or equivalent & 8 \\
\hline Year 12 or equivalent & 4 \\
\hline Certificate & 11 \\
\hline Advanced Diploma/Diploma & 3 \\
\hline Bachelor's Degree & 3 \\
\hline Grad Dip/Grad Cert & 3 \\
\hline Master's Degree & 2 \\
\hline \multicolumn{2}{|l|}{ Ethnicity } \\
\hline Australian & 31 \\
\hline Torres Strait Islander/Aboriginal & 1 \\
\hline Australian Aboriginal & 2 \\
\hline \multicolumn{2}{|l|}{ Employment Status } \\
\hline Casual employment & 7 \\
\hline Full-time employment & 9 \\
\hline Home duties & 8 \\
\hline Part-time employment & 9 \\
\hline Unemployed & 1 \\
\hline \multicolumn{2}{|l|}{ Marital Status } \\
\hline Defacto & 4 \\
\hline Divorced & 6 \\
\hline Married & 17 \\
\hline Single-never married & 7 \\
\hline
\end{tabular}

\subsection{Insulin Treatment Satisfaction Questionnaire}

The modified version of this validated questionnaire was to determine the satisfaction of the child's insulin treatment, as perceived by their parents. The means and standard deviations are presented in Table 3. Overall, parents indicated that they were "confident" that their child could avoid symptoms of overall hypoglycemia. Parents with fMDI felt most confident with their child being able to avoid severe hypoglycemia that could result in loss of consciousness, in comparison to the least confident group of 'MDIs', $\mathrm{t}(21)=$ 2.12, $p=.046$. Parents were "somewhat worried" in relation to their child experiencing nocturnal hypoglycemia. There was, however, no statistically significant difference noted between the treatment regimen with the most worry (fMDI) and the least worry (MDI), $\mathrm{t}(19)=1.02, p=0.323$. The 
overall ease of current insulin regimen was reported "very easy" and there was again, no significant statistical difference noted between the treatment regimen with the most ease (fMDI) with the least ease (MDI), $\mathrm{t}(18)=0.42, p=0.678$. Parents reported their children's overall convenience of taking insulin when away from home as "very convenient" and there was no significant difference noted between the treatment regimen with the most convenience (MDI) and with the least convenience (CSII), t $(21)=1.82, p=0.084$. Parents perceived the pain and discomfort experienced by their children (for all?) as "mild" and there was no significant difference noted between the regimen causing most pain and discomfort (CSII) and least pain and discomfort (fMDI), $\mathrm{t}$ $(15)=1.54, p=0.145$. Most parents felt "somewhat comfortable" in their child's level of comfort while taking insulin in a public place and there was no statistical difference noted between the treatment regimen perceived to be most comfortable (CSII) and with the least comfortable (MDI), $\mathrm{t}(22)=1.62, p=0.119$. The amount of emotional distress or anxiety reported by parents on behalf of their child, overall, was "mild" and there was no significant difference noted between the treatment regimen with the most emotional distress or anxiety (CSII) and with the least emotional distress or anxiety (fMDI), $\mathrm{t}(14)=1.80, p=$ 0.093 .

\subsection{Diabetes Treatment Satisfaction Questionnaire}

The modified version of this validated questionnaire was to determine the satisfaction with the child's overall diabetes regimen of treatment, as perceived by their parents. The means and standard deviations are presented in Table 4. It was reported that overall, parents were "satisfied" with their child's current treatment and there was a significant difference noted between the treatment regimen with the most satisfaction (fMDI) and the treatment regimen with the least satisfaction (CSII), $\mathrm{t}(14)=2.56, p=0.022$. The parents reported, overall, that they felt their child experienced hyperglycemia "some of the time" and there was a significant difference noted between the treatment regimen with the most time with hyperglycemia (fMDI) and with the least time with hyperglycemia (MDI), t $(21)=2.11, p=0.047$. Parents reported, that they felt their child experienced hypoglycemia "not a lot of the time". There was again, a significant difference noted between the treatment regimen with the most time with hypoglycemia (fMDI) and least time with hypoglycemia (MDI), $\mathrm{t}(21)=2.58, p=0.018$. The convenience of the treatment regimens overall was rated as "somewhat convenient" by the parents. There was no statistically significant difference noted between the treatment regimen identified as providing the most convenience (CSII) and the least convenience (fMDI), t (19) $=0.268, p=0.791$. Parents rated their child's treatment overall as "flexible". There was no significant difference noted between the treatment regimen identified as providing the most flexibility (MDI) and with the least flexibility (fMDI), $\mathrm{t}(18)=0.71, p=0.484$. When asked if the parents would recommend their child's treatment regimen, the consensus was "I would most likely recommend". There was, however, a significant difference noted between the treatment regimen with the most recommendation value (CSII) and the treatment regimen with the least recommendation value (MDI), $\mathrm{t}(18)=2.35, p=0.031$. Finally, parents indicated, overall, that they would be "mostly satisfied" to continue with their child's current treatment regimen. There was, however, a significant difference noted between the treatment regimen which they would most likely to continue (CSII) vs least likely to continue (MDI), t $(20)=2.12, p=0.047$.

\section{Limitations}

1. Small sample size.

2. Not being able to utilize an appropriate 'purpose-built' validated tool to capture parental satisfaction. No validated tool was available to assess the satisfaction of parents whose children were treated for T1D. We used modified version of ITSQ and DTSQ to capture the parents' perspective about their children's treatment regimen.

However, the WEll-being and Satisfaction of CAREgivers of Children with Diabetes Questionnaire-WE-CARE, has recently been developed which is going through additional validation processes. (7).

3. Modes of glucose estimation were not looked at. Children were using different glucose monitoring strategies like finger-prick glucometer, flash glucometer, CGM- all of which have the potential to influence parental satisfaction.

4. Potential for selection bias- Parental cognitive and socioeconomic characteristics influence the decision made regarding the type of insulin therapy regimen being selected (i.e., availability of private health insurance, parental education and motivation etc.).

Table 2. Demographic Information of Children with Type 1 Diabetes.

\begin{tabular}{ll}
\hline Variables & $\boldsymbol{n}=\mathbf{3 5}$ \\
\hline Age & \\
$2-4$ & 2 \\
$5-8$ & 1 \\
$9-12$ & 12 \\
$13-18$ & 19 \\
Gender & \\
Female & 18 \\
Male & 17 \\
BMI & \\
$11-15$ & 1 \\
$16-20$ & 17 \\
$21-25$ & 9 \\
$26-30$ & 6 \\
$>30$ & 2 \\
HbA1C & \\
$>9.0 \%$ & 15 \\
$8.6 \%-9.0 \%$ & 7 \\
$8.1 \%-8.5 \%$ & 3 \\
$7.6 \%-8.0 \%$ & 5 \\
$6.5 \%-7.5 \%$ & 4 \\
$<6.5 \%$ & 1 \\
Current Treatment & \\
Insulin Pump (CSII) & 11 \\
Flexible Insulin Dosing (fMDI) & 10 \\
Multiple Daily Injections (MDI) & 14 \\
\hline
\end{tabular}




\section{Discussions}

The prevalence of T1D in Australia is 139 cases per 100,000 population placing it as the 10th highest among the 34 OECD countries. Fortunately, the incidence rate of T1D has not risen in Australia over the last 15 years. Tasmania has the highest prevalence of T1D in children among all the Australian states, being 166 per 100,000 population. [1] Our study was conducted in a regional center in Tasmania and its demographic characteristics were overall similar with the national average as per the Australian Institute of Health and Welfare, 2013 report. T1D were similar for both boys and girls. Incidence rates for children aged 10-14years were 10 times higher than rates for children aged 0-4years. Nationally, just over 2 in 5 children (43\%) with T1D used CSII to administer insulin, as opposed to one-third in our cohort. This may be reflective of the lower socioeconomic population within our region with less access to private health insurance.

Over time, insulin treatment regimen has changed worldwide with the primary aim to improve glycemic control. In MDI, fixed dose long-acting basal insulin injection is given separately, in addition to the fixed number of meal-time boluses. A meal bolus should be given ideally 15 minutes before meals. When compared to MDI, CSII offers added advantage requiring less injection prick (1 x every 2-3 days) but more importantly, can give variable basal rate to match the physiological pattern. Correction dose can also be given without an extra injection. Not everyone with T1D wishes to undertake CSII or does not have the financial means to do so. Flexible multiple daily injection (fMDI), has been developed as an alternative means of delivering intensive insulin therapy. This regimen involves insulin delivered in a dose specific to the amount of carbohydrate intake during meal. A study in the UK suggested that the training promoting dietary freedom involving carbohydrate counting is effective in improving QoL and glycemic control in people with T1D without increasing severe hypoglycemia. [8] In another study in 2002, at the Children's Hospital of Wisconsin Diabetes Center, USA, demonstrated a significant improvement in HbAlc in prepubertal $(9.3 \% \pm 1.3 \%$ vs. $8.0 \% \pm 1.1 \%$, $p<0.002)$ and pubertal subjects $(9.2 \% \pm 1.0 \%$ vs. $8.2 \% \pm 0.9 \%$, $p<0.001$ ) with fMDI compared to the conventional therapy. Most importantly, the rate of severe hypoglycemia was decreased in both prepubertal $(p<0.01)$ and pubertal $(p<0.05)$ groups. [9] Our study echoed similar findings from a parents' perspective- parents of children using fMDI were more confident in avoiding severe hypoglycemia in their children. However, there was higher episodes of asymptomatic hypoglycemia and higher glycemic variability in this group than MDI or CSII. This higher variability associated with fMDI is likely due to inconsistent carbohydrate counting leading to improper meal-time dose adjustment or not consuming all carbohydrates bloused for.

Selecting the right insulin therapy is often quite challenging. There is a need for an ideal insulin regimen that is less restrictive and burdensome with lower risk of hypoglycemia, especially severe hypoglycemia, which can be life-threatening. Despite the availability of three distinct types of insulin therapy, glycemic control largely remains suboptimal in Pediatric populations among adolescents. This is likely due to nonadherence and lack of meal-time dose adjustment. In a multicentric survey-based study among physicians and patients, in the USA, it was found that nearly one third of patients reported insulin omission at least 1 day in the previous month, with an average of 3.3 days insulin omission. Three quarters of physicians reported a mean of 4.3 days per month of basal insulin omission and 5.7 days per month of meal-time insulin omission. Patients and providers, in this study, indicated that the five most common reasons for insulin non-adherence were: being too busy, travelling, skipped meals, stress emotional problems and public embarrassment. [10] Our study identified that there is little difference between the three types of insulin therapy regarding parental stress and anxiety, fear of asymptomatic hypoglycemia, convenience of taking insulin when away from home and ease of use without any significant pain and discomfort. Most physicians report that many insulin-treated patients do not have adequate glucose control (87.6\%) and that they would treat more aggressively if there was no concern about severe hypoglycemia $(75.5 \%)$. In this regard, our study added value suggesting the selection of fMDI may be more appropriate as more parents in this group indicated they had more confidence in avoiding severe hypoglycemia. [10] Higher frequency of severe hypoglycemia often leads to over-treated hyperglycemia and higher variability, therefore, poor overall glycemic control. Psychosocial screening has been recommended for pediatric patients with newly diagnosed T1D and their families. This is a feasible tool to identify families at risk for early emerging complications and nonadherence. [11] As previously discussed one of the most important stressors related to diabetic treatment is the fear of hypoglycemia. In a cross-sectional, population-based study on the parents of 325 children with T1D it was found that the parents with the highest levels of fear of hypoglycemia had higher number of children with reduced QoL $(\mathrm{P}<0.001)$. Likewise, higher episodes of severe hypoglycemia were associated with an increased fear of hypoglycemia for the parents $(\mathrm{P}=0.004)$. The insulin regimen with a greater chance of avoiding severe hypoglycemia in these families may improve their confidence and treatment satisfaction. [12].

Various insulin regimen brings different challenges to family life. Carbohydrate counting, for example, is an extremely important component of good T1D management and is a definite requirement for fMDI and CSII to be successful. [13] Carbohydrate counting can be considered as an added cognitive and affective challenge to the family. Our study indicated that overall the parents felt their children tolerated the insulin therapy well with minimal pain and discomfort without any difference among the various types of insulin therapy. Parents were overall 
"satisfied" with their child's current treatment and found the current insulin regimen was convenient and flexible. Interestingly, parents with fMDI were found to be more satisfied than others, however, parents of CSII group were more likely to recommend to others, potentially reflecting a selection bias. In a similar comparative study conducted in UAE, about the treatment satisfaction and health perception in children and adolescents with T1D on MDI, CSII and sensor-augmented pump therapy, it was found that CSII users had a higher treatment satisfaction and better health perception than those on MDI. Authors concluded that augmenting pump therapy with sensor use added value to treatment satisfaction without correlation with the duration of the sensors use. [14] fMDI was not compared in the study. In addition to the types of insulin regimen and delivery systems, other factors which potentially impact parental satisfaction include the method of administration of MDI, presence of CGM, sensor augmented pump systems and artificial pancreatic system (closed loop system). In a multicenter, randomized, controlled, crossover study, it was demonstrated that adding CGM to pump therapy significantly improves metabolic control but found no significant impact on the overall health related QoL in children. [15] Parental satisfaction was not assessed. Similarly, compared to the vial and syringe method of insulin administration, pens provide more accurate dosing which is particularly important in children - thereby improving short-term and potentially long-term outcomes, parent's confidence and satisfaction. [16] The artificial pancreatic system is a revolutionized concept and is expected to improve parental satisfaction as well as, glycemic control. Experiences of parents of 5-8-year-old children with T1D participating in a clinical trial on the use of artificial pancreas (AP) suggests a strong likelihood of future parental acceptance. [17] An extension of our study in the future comparing the AP with other modes of intensive insulin therapy would be very intriguing. It should be noted that types of insulin can also play an important role in parental satisfaction. Insulin detemir, for instance, is a basal insulin analogue that causes less weight gain than other basal insulin formulations, including the intermediatelong acting Neutral Protamine Hagedorn (NPH) insulin.(18) Parents also preferred prandial insulin Aspart for MDI in pre-school children than NPH.(19) In another study comparing CSII and MDI using insulin Aspart with MDI using Human Insulin, it was found all metabolic control parameters remained unchanged and equivalent, but most importantly caregiver treatment satisfaction was higher in parents who chose insulin Aspart containing CSII therapy. (20) A telephone-based intervention focusing on child development, coping, and problem-solving skills has the potential to positively impact parents' QoL and may have implications for improving children's health as well as their QoL. [21].

Table 3. Insulin Treatment Satisfaction Questionnaire Results.

\begin{tabular}{|c|c|c|c|c|c|c|c|c|}
\hline \multirow[t]{2}{*}{ Item } & \multicolumn{2}{|c|}{ Overall } & \multicolumn{2}{|c|}{$\begin{array}{l}\text { Flexible Insulin } \\
\text { Dosing }\end{array}$} & \multicolumn{2}{|c|}{$\begin{array}{l}\text { Multiple Daily } \\
\text { Insulin (MDI) }\end{array}$} & \multicolumn{2}{|c|}{ Insulin Pump } \\
\hline & $\mathbf{n}$ & Mean (SD) & $\mathbf{n}$ & Mean (SD) & $\mathbf{n}$ & Mean (SD) & $\mathbf{n}$ & Mean (SD) \\
\hline $\begin{array}{l}\text { How confident are you that your child can avoid symptoms of } \\
\text { low blood sugar with their current insulin treatment? }\end{array}$ & 34 & $2.7(1.7)$ & 10 & $3.1(1.6)$ & 14 & $2.1(1.4)$ & 11 & $3.2(1.8)$ \\
\hline $\begin{array}{l}\text { How confident are you that your child can avoid severe episodes } \\
\text { of low blood sugar that result in loss of consciousness with the } \\
\text { insulin they currently use? }{ }^{*}\end{array}$ & 34 & $2.3(1.4)$ & 10 & $2.8(1.1)$ & 14 & $1.7(1.3)$ & 11 & $2.5(1.4)$ \\
\hline $\begin{array}{l}\text { How worried are you about your child experiencing low blood } \\
\text { sugar during the night with the insulin that they currently use? }\end{array}$ & 34 & $3.2(1.5)$ & 10 & $3.5(1.6)$ & 14 & $2.8(1.5)$ & 11 & $3.4(1.4)$ \\
\hline $\begin{array}{l}\text { How easy is it for your child to take the correct amount of } \\
\text { insulin each time with the insulin they currently use? }\end{array}$ & 34 & $2.4(1.6)$ & 10 & $2.3(0.8)$ & 14 & $2.5(1.8)$ & 11 & $2.5(1.9)$ \\
\hline $\begin{array}{l}\text { How convenient is your child's current method of taking insulins } \\
\text { when they are away from home? }\end{array}$ & 34 & $2.3(1.5)$ & 10 & $2.2(0.8)$ & 14 & $2.8(1.9)$ & 11 & $1.6(1.3)$ \\
\hline $\begin{array}{l}\text { How much pain or other physical discomfort do you think your } \\
\text { child experiences with their current method of taking insulin? }\end{array}$ & 34 & $3.0(1.3)$ & 10 & $2.7(1.3)$ & 14 & $2.8(1.6)$ & 11 & $3.5(0.8)$ \\
\hline $\begin{array}{l}\text { How comfortable do you think your child is while taking insulin } \\
\text { in a public place (where people might see them) with their } \\
\text { current method of taking insulin? }\end{array}$ & 34 & $3.1(2.0)$ & 10 & $2.8(1.5)$ & 14 & $3.9(2.1)$ & 11 & $2.5(2.0)$ \\
\hline $\begin{array}{l}\text { How much emotional distress or anxiety do you experience } \\
\text { related to your child's method of taking insulin? }\end{array}$ & 34 & $3.1(1.7)$ & 10 & $2.4(0.8)$ & 14 & $3.3(2.0)$ & 11 & $3.5(1.9)$ \\
\hline
\end{tabular}

\section{Conclusion}

The study did not find any statistically significant difference between the insulin regimens regarding parental perception of their children's asymptomatic daytime and nocturnal hypoglycemic episodes, ease of use, flexibility and convenience, pain and discomfort, use of insulin in public places and parents' own stress and anxiety. A larger sample size using a purpose-built validated tool would be required in future with possible inclusion of closed-loop system. However, this study identified a significant difference in parental confidence in avoiding severe hypoglycaemia when using fMDI. This finding could be utilized in the subgroup of parents who have a significant fear of hypoglycaemia impacting on their child's glycaemic control. Accurate carbohydrate counting, and appropriate meal-time dose adjustment may be the key to success and can be difficult to achieve for some families. 


\section{Abbreviation}

T1D: type 1 diabetes mellitus, MDI: Multiple Daily Injection, CSII: Continuous Subcutaneous

Insulin Infusion, fMDI: Flexible Multiple Daily Injection, HbAlc: Glycosylated hemoglobin,
ITSQ: Insulin treatment satisfaction Questionnaire, DTSQ: Diabetes treatment satisfaction Questionnaire, SH: Severe Hypoglycaemia, DKA: Diabetic Ketoacidosis, CGM: Continuous Glucose Monitoring, HRQoL: Health Related Quality of Life, AP: Artificial Pancreatic System.

Table 4. Diabetes Treatment Satisfaction Questionnaire Results.

\begin{tabular}{|c|c|c|c|c|c|c|c|c|}
\hline \multirow[t]{2}{*}{ Item } & \multicolumn{2}{|c|}{ Overall } & \multicolumn{2}{|c|}{$\begin{array}{l}\text { Flexible Insulin } \\
\text { Dosing }\end{array}$} & \multicolumn{2}{|c|}{$\begin{array}{l}\text { Multiple Daily } \\
\text { Insulin (MDI) }\end{array}$} & \multicolumn{2}{|c|}{ Insulin Pump } \\
\hline & $\mathbf{n}$ & Mean (SD) & $\mathbf{n}$ & Mean (SD) & $\mathbf{n}$ & Mean (SD) & n & Mean (SD) \\
\hline How satisfied are you with your child's current treatment? * & 34 & $4.9(1.3)$ & 10 & $5.6(0.7)$ & 14 & $\begin{array}{l}4.7 \\
(1.2)\end{array}$ & 11 & $\begin{array}{l}4.3 \\
(1.5)\end{array}$ \\
\hline $\begin{array}{l}\text { How often have you felt that your child's blood sugars have } \\
\text { been unacceptably high recently? } *\end{array}$ & 34 & $3.3(1.7)$ & 10 & $3.9(1.3)$ & 14 & $\begin{array}{l}2.5 \\
(1.8)\end{array}$ & 11 & $\begin{array}{l}3.4 \\
(1.6)\end{array}$ \\
\hline $\begin{array}{l}\text { How often have you felt that your child's blood sugars have } \\
\text { been unacceptably low recently? } *\end{array}$ & 34 & $2.3(1.4)$ & 10 & $3.2(1.2)$ & 14 & $\begin{array}{l}1.8 \\
(1.4)\end{array}$ & 11 & $\begin{array}{l}2.0 \\
(1.3)\end{array}$ \\
\hline $\begin{array}{l}\text { How convenient have you been finding your child's } \\
\text { treatment to be recently? }\end{array}$ & 34 & $4.8(0.9)$ & 10 & $4.8(0.9)$ & 14 & $\begin{array}{l}4.8 \\
(1.0)\end{array}$ & 11 & $\begin{array}{l}4.9 \\
(0.9)\end{array}$ \\
\hline $\begin{array}{l}\text { How flexible have you been finding your child's treatment } \\
\text { to be recently? }\end{array}$ & 34 & $4.8(1.0)$ & 10 & $4.7(1.1)$ & 14 & $\begin{array}{l}5.0 \\
(0.9)\end{array}$ & 11 & $\begin{array}{l}4.7 \\
(1.2)\end{array}$ \\
\hline $\begin{array}{l}\text { Would you recommend your child's type of treatment to } \\
\text { someone else? } *\end{array}$ & 34 & $5.2(1.1)$ & 10 & $5.5(0.7)$ & 14 & $\begin{array}{l}4.6 \\
(1.4)\end{array}$ & 11 & $\begin{array}{l}5.7 \\
(0.7)\end{array}$ \\
\hline $\begin{array}{l}\text { How satisfied would you be to continue with your child's } \\
\text { present form of treatment? } *\end{array}$ & 34 & $5.3(0.9)$ & 10 & $5.6(0.5)$ & 14 & $\begin{array}{l}4.8 \\
(1.1)\end{array}$ & 11 & $\begin{array}{l}5.6 \\
(0.7)\end{array}$ \\
\hline
\end{tabular}

\section{References}

[1] Aihw. Prevalence of Type I diabetes among children aged 015 in Australia. 2013; (24): 1-24.

[2] Nathan DM. The diabetes control and complications trial/epidemiology of diabetes interventions and complications study at 30 years: Overview. Diabetes Care. 2014; 37 (1): 9 16.

[3] Li YLA. Quality of Life in Parents of Children with Type 1 Diabetes Receiving Insulin Treatment. [Internet]. Quality of Life in Parents of Children with Type 1 Diabetes Receiving Insulin Treatment. 2014.

[4] Szypowska A, Schwandt A, Svensson J, Shalitin S, CardonaHernandez R, Forsander G, et al. Insulin pump therapy in children with type 1 diabetes: analysis of data from the SWEET registry. Pediatr Diabetes. 2016; 17: 38-45.

[5] Opipari-arrigan L, Fredericks EM, Burkhart N, Dale L, Hodge $\mathrm{M}$, Foster C. Continuous subcutaneous insulin infusion benefits quality of life in preschool-age children with type 1 diabetes mellitus. Pediatr Diabetes. 2007; 8 (6): 377-83.

[6] Hughes CR, McDowell N, Cody D, Costigan C. Sustained benefits of continuous subcutaneous insulin infusion. Arch Dis Childhood [Internet]. 2010; 25.

[7] Cappelleri JC, Gerber RA, Quattrin T, Deutschmann R, Luo X, Arbuckle R, et al. Development and validation of the WEllbeing and Satisfaction of CAREgivers of Children with Diabetes Questionnaire (WE-CARE). Health Qual Life Outcomes. 2008 Jan; 6: 3.

[8] Group DS. Training in flexible, intensive insulin management to enable dietary freedom in people with Type 1 diabetes: dose adjustment for normal eating (DAFNE) randomized controlled trial. Diabet Med. 2003;20 Suppl 3:4-5.
[9] Alemzadeh R, Palma-Sisto P, Parton E, Totka J, Kirby M. Beneficial effects of flexible insulin therapy in children and adolescents with type 1 diabetes mellitus. Acta Diabetol. 2003; 40 (3): $137-42$.

[10] Peyrot M, Barnett AH, Meneghini LF, Schumm-Draeger PM. Insulin adherence behaviours and barriers in the multinational Global Attitudes of Patients and Physicians in Insulin Therapy study. Diabet Med. 2012; 29 (5): 682-9.

[11] Schwartz DD, Cline VD, Axelrad ME, Anderson BJ. Feasibility, acceptability, and predictive validity of a psychosocial screening program for children and youth newly diagnosed with type 1 diabetes. Diabetes Care. 2011; 34 (2): 326-31.

[12] Johnson SR, Cooper MN, Davis E a, Jones TW. Hypoglycaemia, fear of hypoglycaemia and quality of life in children with Type 1 diabetes and their parents. Diabet Med [Internet]. 2013; 30 (9): 1126-31.

[13] Diabetes P. The importance of carbohydrate counting in the treatment of children with diabetes The importance of carbohydrate counting in the treatment of children with diabetes. 2015; 8 (NOVEMBER 2007): 57-62.

[14] Hussain T, Akle M, Nagelkerke N, Deeb A. Comparative study on treatment satisfaction and health perception in children and adolescents with type 1 diabetes mellitus on multiple daily injection of insulin, insulin pump and sensoraugmented pump therapy. SAGE Open Med [Internet]. 2017; 5:205031211769493.

[15] H. G, J. C, E. H, B. S. O, T. B, I. C, et al. The switch study: The impact of continuous glucose monitoring on quality of life and treatment satisfaction [Internet]. Vol. 15, Value in Health. 2012. p. A359.

[16] Barnard KD, Wysocki T, Ully V, Mader JK, Pieber TR, Thabit H, et al. Insulin pump therapy: impact on the lives of children/young people with diabetes mellitus and their parents. Int J Clin Pharm. 2008 Nov; 105 (11): 927-31. 
[17] A. T, R. B, D. I, et al. The social acceptance of future artificial pancreas technology: Parents' perceptions of pedarpan (pediatrics artificial pancreas). Diabetes Ther [Internet]. 2016; 18: A46--A47.

[18] van Golen LW, Veltman DJ, IJzerman RG, Deijen JB, Heijboer AC, Barkhof F, et al. Effects of Insulin Detemir and NPH Insulin on Body Weight and Appetite-Regulating Brain Regions in Human Type 1 Diabetes: A Randomized Controlled Trial. PLoS One [Internet]. 2014; 9 (4): e94483.

[19] Danne T, Rstam J, Odendahl R, et al. Parental preference of prandial insulin aspart compared with pre-prandial human insulin in a basal-bolus scheme with NPH insulin in a 12-wk crossover study of preschool children with type 1 diabetes. Pediatr Diabetes. 2007; 8 (5): 278-85.

[20] Pańkowska E, Nazim J, Szalecki M, Urban M. Equal Metabolic Control but Superior Caregiver Treatment Satisfaction with Insulin Aspart in Preschool Children. Diabetes Technol Ther [Internet]. 2010; 12 (5): 413-8.

[21] Monaghan M, Hilliard ME, Cogen FR, Streisand R. Supporting parents of very young children with type 1 diabetes: Results from a pilot study. Patient Educ Couns. 2011; 82 (2): $271-4$. 